\title{
THE EORTC QUALITY OF LIFE QUESTIONNAIRE QLQ-C30 (VERSION 3.0). VALIDATION STUDY FOR SPANISH PROSTATE CANCER PATIENTS
}

Juan Ignacio Arraras Urdaniz',2, Elena Villafranca Iturre', Fernando Arias de la Vega', Miguel Angel Domínguez Domínguez', Nuria Lainez Milagro², Ana Manterola Burgaleta', Enrique Martinez Lopez', Pilar Romero Rojano' y Maite Martinez Aguillo².

Radiotherapeutic Oncology Department' and Medical Oncology Department². Hospital of Navarre. Irunlarrea. Pamplona. Spain.

Summary.- OBJECTIVE: The EORTC Quality of Life Group has developed a questionnaire for evaluating Quality of Life in international clinical trials: EORTC QLQ-C30, which is widely used in many countries. The purpose of this study was to assess the psychometric properties of the third version of this questionnaire, EORTC QLQ-C30 (version 3.0), when applied to Spanish prostate cancer patients.

METHODS: A sample of 137 prostate cancer patients prospectively filled in the questionnaire three times: on the first and last day of the treatment, and in the followup period. Psychometric evaluation of the structure, reliability and validity was made.
RESULTS: Multitrait scaling analysis showed that most item-scale correlation coefficients met the standards of convergent and discriminant validity. Few exceptions appeared mainly in CF. Most scales had low to moderate inter-correlations. Cronbach's coefficients of the scales were above 0.7, except for the CF and NV values. Group comparison analyses showed better QL in patients with higher Performance Status. Changes in functioning and symptom areas appeared throughout the different measurements, which were in line with the treatment process.

CONCLUSIONS: The EORTC QLQ-C30 (version 3.0) appeared as a reliable and valid instrument when applied to a sample of Spanish prostrate cancer patients. The results are in line with previous studies.

Keywords: Cancer. Prostate. Quality of Life. Validation. Spanish. EORTC QLQ-C30.

Resumen.- OBJETIVO: El Grupo de Calidad de Vida de la EORTC ha desarrollado un cuestionario para evaluar la Calidad de Vida en ensayos clínicos internacionales: EORTC QLQ-C30, el cual es ampliamente utilizado en muchos países. El objetivo de este trabajo es evaluar las propiedades psicométricas de la tercera versión de este cuestionario, EORTC QLQ-C30 /versión 3.Ol, al ser administrado a pacientes españoles con cáncer de próstata.

MÉTODOS: Una muestra de 137 pacientes con cáncer de próstata han contestado el cuestionario de forma prospectiva tres veces: el primer y último día de tratamiento, y durante el período de seguimiento. Se ha 
realizado una evaluación psicométrica de su estructura, fiabilidad y validez.

RESULTADOS: los análisis multirasgo - multimétodo han mostrado que la mayoría de las correlaciones ítem-escala satisfacían los criterios de validez convergente y divergente. Se han dado pocas excepciones, principalmente en la escala CF. La mayoría de las correlaciones entre escalas eran bajas o moderadas. Los coeficientes Alpha de Cronbach de las escalas eran superiores a 0,7 , excepto en las escalas CF y NV. Los análisis de comparación entre grupos han indicado que se da una mejor Calidad de Vida en pacientes con mayor performance status. Se han dado cambios en áreas de funcionamiento y de síntomas a lo largo de las diferentes medidas, que han ido en línea con el proceso de tratamiento.

CONCLUSIONES: el EORTC QLQ-C30 (versión 3.0) se ha mostrado como un instrumento fiable y válido al ser aplicado a una muestra de pacientes españoles con cáncer de próstata. Los resultados van en línea con los estudios de validación previos.

Palabras clave: Cáncer. Próstata. Calidad de Vida. Validación. Español. EORTC QLQ-C30.

\section{INTRODUCTION}

Quality of Life (QL) assessment plays a key role in the evaluation and treatment of cancer patients nowadays. The European Organization for Research and Treatment of Cancer - EORTC has a working group on QL. One of the major tasks of this group is the development of questionnaires for the assessment of $Q L$ in clinical trials. These instruments can also be used in clinical practice. This QL group has created a combined assessment system composed of a generic core questionnaire, EORTC QLQ-C30, which evaluates issues common to different cancer sites and treatments, and a range of supplementary modules designed to assess specific issues, according to type of treatment or disease site, or to dimensions like fatigue. The EORTC QLQ-C30 has been internationally validated, translated into more than 48 languages, and is widely requested and used in Spain and other Spanish speaking countries. The EORTC QL Study Group recommends carrying out validation studies of the QLQ-C30 in individual countries and with different tumor sites and stages 1,2 . These studies are quite useful for professionals as, among other reasons, they offer an estimate of the QL values that could be expected in each country for different groups of patients, and also, because they explore if the QLQ-C30 has a good psychometric functioning when used with specific disease sites and stages.
Validation studies for Spain of the QLQ-C30 (version 3.0) 3 with head and neck cancer patients and of the previous versions (1.0 and 2.0) 4-6 have been undertaken at the Radiotherapeutic Oncology and Medical Oncology Departments of the Hospital of Navarre.

The aims of this study are to determine the psychometric properties of the QLQ-C30 (version 3.0) when applied to a sample of Spanish prostate cancer patients, and to compare the results of these analyses with those of the previous validation studies carried out by us, and by the EORTC QL study group.

\section{MATERIALS AND METHODS}

\section{Participants}

A consecutive sample of prostate cancer patients was included. This sample consisted of patients with localized disease (T1-T3 NO MO) who started radiotherapy with radical intention combined or not with hormotherapy at the Radiotherapeutic Oncology Department of the Hospital of Navarre.

\section{Measures}

Patients completed the QLQ-C30 (version 3.0). The structure of this questionnaire is presented in Table I. It had been translated into Spanish following the EORTC QL Study Group translation procedure 7. Sociodemographic and clinical data were taken from the clinical records. Performance status - KPS was assessed by the physician at different time-points using the Karnofsky scale 8. Questionnaires with less than $70 \%$ of the items answered were excluded.

\section{TABLE I. STRUCTURE OF THE EORTC QLQ-C3O.}

\begin{tabular}{|l|l|}
\hline $\begin{array}{l}\text { Functional } \\
\text { scales (1) }\end{array}$ & $\begin{array}{l}\text { Physical functioning PF, role } \\
\text { functioning RF, emotional } \\
\text { functioning EF, cognitive } \\
\text { functioning CF, social } \\
\text { functioning SF, global QL GQL. }\end{array}$ \\
\hline $\begin{array}{l}\text { Symptoms and } \\
\text { side effects } \\
\text { scales and } \\
\text { items (2) }\end{array}$ & $\begin{array}{l}\text { Scales: Fatigue FA, nausea and } \\
\text { vomiting NV, pain PA. } \\
\text { Items: dyspnoea DY, sleep } \\
\text { disturbance SL, appetite loss AP, } \\
\text { constipation CO, diarrhoea DI, } \\
\text { financial impact Fl }\end{array}$ \\
\hline
\end{tabular}

Functional scales (1), the scores range from 0 to 100 , with a higher score representing a higher level of functioning. Symptoms and side effects scales and items (2), scores ranging from $\mathrm{O}$ to 100 , with a higher score representing a higher level of symptoms and side effects. 


\section{Data collection procedures}

Patients completed the QLQ-C30 on the first and last day of radiotherapy, and one month and a half after the end of this particular treatment.

\section{Statistical analysis}

Multitrait scaling analysis 9 was employed to examine item convergent validity (item scale correlation > 0.40 , scale corrected for overlap) and item discriminant validity (item own scale correlation higher that with the other scales).

Internal consistence reliability of the scales was assessed with Cronbach's alpha coefficient 10 (> 0.70 criteria).

Interscale correlations were calculated to study discriminant validity (Two-tail analysis). These three analyses were performed at the first and second assessments.

Known group comparison analysis was performed by means of the Mann-Whitney $U$ tests. We compared subgroups based on KPS levels: 70 to 90 and 100 in the first and third measurements; 70 to 80 and 90 to 100 in the second.
Responsiveness to change over time We studied the differences among the three measurements (Friedman test $p<0.01$ and Bonferroni criteria to see between which pairs of measurements the differences appeared).

\section{RESULTS}

Patients' characteristics and compliance 137 patients from a total of 141 that were addressed filled in the first questionnaire, 132 did the second one and 126 answered the third one. All questionnaires had more than $70 \%$ of items answered. Their sociodemographic and clinical characteristics are presented in Table II, and their scores in the QLQ-C30 in Tables III.

Multitrait scaling analysis Most items exceeded the 0.4 criterion for convergent validity on all scales. Exceptions were items 20 and 25 in the first measurement, and 4, 14 and 15 in the second. Item discriminant validity was successful in all analyses except in item 5 (higher correlation with SF than with its own scale), item 10 (higher correlation with PF) in the first measurement, and in the second assessment, item 20 (higher correlations with EF and SF).

Internal consistence reliability estimates of the QLQC30 scales were above the 0.70 criteria for most sca-

TABLE II. CHARACTERISTICS OF THE SAMPLE.

\begin{tabular}{|l|l|l|l|l|}
\hline & Number & Mean & S. D. & $\%$ \\
\hline Age & & 70,9 & 5,2 & \\
\hline Level of studies & & & & \\
\hline Less than compulsory school education & 44 & & & 32,1 \\
\hline Compulsory school education & 75 & & & 54,7 \\
\hline Post compulsory education below university & 8 & & & 5,8 \\
\hline University level & 10 & & & 7,4 \\
\hline Hormotherapy & & & & \\
\hline Yes & 117 & & & 85,4 \\
\hline No & 20 & & & 14,6 \\
\hline Karnofsky 1 & & 96,1 & 6,1 & \\
\hline Karnofsky 2 & & 87,6 & 6,7 & \\
\hline Karnofsky 3 & & 91,8 & 7,6 & \\
\hline
\end{tabular}


les in both measurements: PF (0.76 - 0.73), RF $(0.86$ $0.90)$, EF (0.79 - 0.81), SF (0.89-0.71), GQL (0.87 - 0.95), FA (0.84 in both), PA (0.73 -0.84), with the exception of CF (0.48 - 0.57) and NV (0.45 - 0.39).

Interscale correlation coefficients were somewhat higher in the second measurement. Most scales had low to moderate correlations with the other scales. The highest correlations were between FA and PF (- 0.71 first measurement, - 0.63 second), RF (- 0.65 and - 0.62), EF (- 0.51 and - 0.57), and between PF and RF (0.65 in both), and SF (0.57 - 0.50). Low correlations were found between NV with PF $(-0.13$ and -0.251 .

Group comparisons In the analyses performed with KPS as grouping variable significant differences appeared in SF in the first measurement, in PF in the second, and in PF, RF, FA, PA and GQL in the third.

Responsiveness to change There was a significant worsening of the condition between the first and the second measurements in five areas $(\mathrm{PF}, \mathrm{PA}, \mathrm{CO}, \mathrm{DI}$, FA), a significant improvement between the second and third measurements, with no significant differences between the first and third questionnaires. There was a significant worsening in CF and SF between the first and second measurements, and in GQL between the second and third measurements. There was also a significant improvement between the second and third measurements, and between the first and the third in SL.

\section{DISCUSSION}

In this paper we have presented the results of a validation study of the EORTC QLQ-C30 (version 3.0) questionnaire for Spain with a sample of prostrate cancer. The scores in the QLQ-C30 [table 3] were in line with, and just a bit better than the ones recorded in the reference manual 11 . Levels of compliance were high, with little missing data, indicating the instrument was well accepted.

TABLE III. QUALITY OF LIFE SCORES ACCORDING TO QLQ-C3O.

\begin{tabular}{|l|l|l|l|l|l|l|l|}
\hline \multicolumn{4}{|c}{ 1 measurement } & \multicolumn{3}{c|}{ 2 measurement 3 measurement } \\
\hline Areas & Items & Mean & S.D. & Mean & S.D. & Mean & S.D. \\
\hline (1)Physical & $1-5$ & 91.7 & 14,6 & 88,8 & 15,3 & 91,9 & 13,3 \\
\hline (1)Role & $6-7$ & 93,5 & 18,4 & 88,5 & 23,6 & 92,7 & 19,7 \\
\hline (1)Emotional & $21-24$ & 87,6 & 16,8 & 85,2 & 18,5 & 90,1 & 17,1 \\
\hline (1)Cognitive & $20-25$ & 95,4 & 10,6 & 90,5 & 16,7 & 93,1 & 15 \\
\hline (1)Social & $26-27$ & 96,3 & 13,3 & 92,7 & 15,9 & 94,8 & 12,5 \\
\hline (1)Global & $29-30$ & 66,8 & 17,9 & 66,7 & 20,9 & 71,3 & 18,6 \\
\hline (2)Fatigue & $10,12,18$ & 9,7 & 17,8 & 20,1 & 22,9 & 11,3 & 19,5 \\
\hline (2)Nausea, vomiting. & 14,15 & 0,9 & 4,4 & 1,6 & 6,4 & 0,9 & 5,1 \\
\hline (2)Pain & 9,19 & 10,6 & 20,3 & 17,7 & 24,4 & 11,3 & 20,3 \\
\hline (2)Dispnoea & 8 & 4,3 & 13,8 & 6,3 & 16,2 & 3,1 & 10,7 \\
\hline (2)Sleep disturbance & 11 & 21,8 & 30,3 & 23,5 & 28,9 & 15,5 & 24,5 \\
\hline (2)Appetite loss & 13 & 4,8 & 15,4 & 7,8 & 18,5 & 3,4 & 12,9 \\
\hline (2)Constipation & 16 & 9,2 & 21,8 & 22,2 & 28,4 & 11,4 & 22,9 \\
\hline (2)Diarrhoea & 17 & 4,8 & 16,1 & 16,7 & 23,9 & 5,8 & 16,3 \\
\hline (2)Financial impact & 28 & 3,8 & 16,6 & 8,1 & 22,3 & 7,4 & 22,2 \\
\hline
\end{tabular}

Mean \pm SDs of the scores in the QLQ-C30, at the three measurements. Functional scales (1), the scores range from 0 to 100, with a higher score representing a higher level of functioning. Symptoms and side effects scales and items

(2), scores ranging from 0 to 100, with a higher score representing a higher level of symptoms and side effects. 
Multitrait scaling analyses confirmed the psychometric structure of the questionnaire, and were in line with previous studies 12-15. Few errors appeared, and they were mainly related to the cognitive functioning scale, as in our previous validation 3-6 and in the Zhao and Kanda 16 studies.

Most scales fulfilled the reliability criteria, except CF and NV. The standard deviation of NV in the two measurements has been low, which may have affected their Alpha coefficient. Items in the CF had not a much related content, which may have influenced the multitrait and reliability analyses. In the validation study of version 3.0 we had carried out with head and neck cancer patients, these two scales also had low Alphas in the pre-treatment measurement 3. CF had also shown low reliability scores in the validation studies we carried out with version 1.0 and 2.0 4-6 and in other studies 1, 12-21, and NV in some of them.

Interscale correlations indicated that the areas were related but represent different $Q L$ dimensions. Areas with more related content, (PF, RF) had higher correlation coefficients in the expected direction, and vice versa, as in the case of NV-PF. Group comparison analyses were satisfactory, as they were in line with the clinical data: patients with higher KPS had better QL. These interscale correlations and known group analyses were in line with our previous 3-6 and other studies 1, 12-16, 22-24.

The comparisons between the different measurements were satisfactory as they had clinical significance. These results showed the QLQ-C30 is highly sensitivity to changes. There was a clear tendency to a worsening at the end of the treatment, with a recovery in most scales in the follow-up measurement that could be due to radiotherapy low toxicity level. In $\mathrm{SL}$, we could consider there has been an emotional adaptation to the disease and treatment.

\section{CONCLUSIONS}

To summarize, the EORTC QLQ-C30 (version 3.0) demonstrated satisfactory psychometric properties when applied to a sample of Spanish patients with prostate cancer. Our results are in line with those of the previous validation studies carried out by our group, and by the EORTC QL study group. We consider that the EORTC QLQ-C30 (version 3.0) is a robust instrument for its use with Spanish cancer patients. New studies with other tumors could have a confirmatory value.

\section{ACKNOWLEDGEMENTS}

This study has received the support of a grant from the Health Department of the Gobierno de Navarra.

\section{Abbreviations:}

Quality of Life (QL)

European Organization for Research and Treatment of Cancer - EORTC

QLQ-C30 scales: physical functioning PF, role functioning $R F$, emotional functioning $E F$, cognitive functioning $C F$, social functioning SF, global QL GQL, fatigue $F A$, nausea and vomiting NV, pain PA.

QLQ-C30 items: DY dyspnoea, SL sleep disturbance, AP appetite loss, CO constipation, DI diarrhea, FI financial impact

Performance status evaluated with Karnofsky KPS.

\section{REFERENCES AND RECOMENDED READINGS (*of special interest, ${ }^{* *}$ of outstanding interest)}

**1. AARONSON, N.K.; AHMEZDAI, S.; BERGMAN, B. y cols.: "The European Organization for Research and Treatment of Cancer QLQ-C30: a Quality of Life instrument for use in intentional clinical trials". J. Natl. Cancer. Inst.; 85: 365, 1993.

*2. AARONSON, N.K.; CULL, A.; KAASA, S. y cols.: "The EORTC modular approach to Quality of Life assessment in oncology". Int. J. Ment. Health.; 23: 75, 1994.

**3. ARRARAS, J.I.; ARIAS, F.; TEJEDOR, M. y cols.: "The EORTC QLQ-C30 (version 3.0) quality of life questionnaire. Validation study for Spain with head and neck cancer patients". Psycho-oncology; 11: 249, 2002.

*4. ARRARAS, J.I.; PRUJA, E.; TEJEDOR, M. y cols.: "El cuestionario de Calidad de Vida de la EORTC, QLQ-C30 (versión 2.0). Estudio estadístico de validación para nuestro país con pacientes con cáncer de pulmón". Rev. Oncol.; 1: 257, 1999.

5. ARRARAS, J.I.; GARRIDO, E.; PRUJA, E. y cols.: "El cuestionario de calidad de vida de la EORTC QLQ-C30 (versión 2.0). Estudio psicométrico con pacientes con cáncer de mama". Clínica Salud; 11: 239, 2000. 
6. ARRARAS, J.I.; ILLARRAMENDI, J,J,; VALERDI, J,J.: "El cuestionario de Calidad de Vida para cáncer de la EORTC, QLQ-C30. Estudio estadístico de validación con una muestra española”. Rev. Psic. Salud; 7: 13, 1995.

*7. CULL, A.; SPRANGERS, M.; BJORDAL, K.; AARONSON, N.K.; WEST, K.: "EORTC Quality of Life Group translation procedure, 2nd Edition". EORTC, Brussels, 2002.

8. KARNOFSKY, D.A.; BURCHENAL, J.H.: "The clinical evaluation of chemotherapeutic agents in cancer". McLeod CM editor: Evaluation of chemotherapeutic agents; 199-205; Colombia University, New York, 1948.

9. WARE, J.E.; HARRIS, W.J.; GANDEK, B.; ROGERS, B.W.; REESE, P.R.: "MAP-R for windows: multitrait multi-item analysis program - revised user's guide". Health Assessment Lab, Boston, MA, 1997.

10. CRONBACH, L.J.: "Coefficient alpha and the internal structure of tests". Psychometrika, 16: 297, 1951.

**11. FAYERS, P.; WEEDEN, S.; CURRAN, D.: "EORTC QLQ-C30. Reference values". EORTC, Brussels, 1998.

*12. OSOBA, D.; ZEE, B.; PATER, J. y cols.: "Psychometric properties and responsiveness of the EORTC quality of Life Questionnaire (QLQ-C30) in patients with breast, ovarian and lung cancer". Qual. Life. Res.; 3: 353, 1994.

*13. HOOPMAN, R.; MULLER, M.J.; TERWEE, C.B. y cols.: "Translation and validation of the EORTC QLQ-C30 for use among Turkish and Moroccan ethnic minority cancer patients in the Netherlands". Eur. J. Cancer.; 42: 1839, 2006.

14. YUN, Y.H.; PARK, Y.S.; LEE, E.S. y cols.: "Validation of the Korean version of the EORTC QLQC30". Qual. Life. Res,; 13: 863, 2004.

15. SILPAKIT, C.; SIRILERTTRAKUL, S.; JIRAJARUS, M. et al.: "The European Organization for Research and Treatment of Cancer Quality of Life Questionnaire (EORTC QLQ-C30): validation study of the Thai version". Qual. Life. Res., 15: 167, 2006.

16. ZHAO, H.; KANDA, K.: "Testing psychometric properties of the standard Chinese version of the European Organization for Research and Treat- ment of Cancer Quality of Life Core Questionnaire 30 (EORTC QLQ-C30)". J. Epidemiol.; 14: 193, 2004.

17. KEMMLER, G.; HOLZNER, B.; KOPP, M. y cols.: "Comparison of two quality-of-life instruments for cancer patients: the functional assessment of cancer therapy-general and the European Organization for Research and Treatment of Cancer Quality of Life Questionnaire-C30”. J. Clin. Oncol.; 17: 2932, 1999.

18. CHIE, W.C.; YANG, C.H.; HSU, C. y cols.: "Quality of life of lung cancer patients: validation of the Taiwan Chinese version of the EORTC QLQC30 and QLQ-LC13". Qual. Life. Res.; 13: 257, 2004.

19. CHIE, W.C.; HONG, R.L.; LAI, C.C. y cols.: "Quality of life in patients of nasopharyngeal carcinoma: validation of the Taiwan Chinese version of the EORTC QLQ-C30 and the EORTC QLQH\&N35". Qual. Life. Res.; 12: 93, 2003.

20. LUO, N.; FONES, C.S.; LIM, S.E. y cols.: "The European Organization for Research and Treatment of Cancer Quality of Life Questionnaire (EORTC QLQ-C30): validation of English version in Singapore”. Qual. Life. Res.; 14: 1181, 2005.

*21. FORD, M.E.; HAVSTAD, S.L.; KART, C.S.: “Assessing the reliability of the EORTC QLQ-C30 in a sample of older African American and Caucasian adults". Qual. Life. Res.; 10: 533, 2001.

22. MONTAZERI, A.; HARIRCHI, I.; VAHDANI, M. y cols.: "The European Organization for Research and Treatment of Cancer Quality of Life Questionnaire (EORTC QLQ-C30): translation and validation study of the Iranian version". Support Care Cancer; 7: 400, 1999.

23. KYRIAKI, M.; ELENI, T.; EFI, P. y cols.: "The EORTC core quality of life questionnaire (QLQ$\mathrm{C} 30$, version 3.0) in terminally ill cancer patients under palliative care: validity and reliability in a Hellenic sample". Int. J. Cancer; 94: 135, 2001.

**24. BJORDAL, K.; DE GRAEFF, A.; FAYERS, P.M. y cols. "A 12 country field study of the EORTC QLQ-C30 (version 3.0) and the head and neck cancer specific module (EORTC QLQ-H\&N35) in head and neck patients". Eur. J. Cancer.; 36: 1796, 2000. 